\title{
Interview with Dr. Miguel Ángel Roca Perara about Psychological Intervention in Cuba: "Human Beings Are Made of a Complicated Substance"
}

\author{
Montse Rovira \\ International Supervisor in Rational-Emotive \& Cognitive Behavior Therapy, Albert Ellis Institute, New York, NY, USA \\ Email: trecseo@gmail.com
}

How to cite this paper: Rovira, M. (2017). Interview with Dr. Miguel Ángel Roca Perara about Psychological Intervention in Cuba: "Human Beings Are Made of a Complicated Substance". Psychology, 8, 1501-1512.

https://doi.org/10.4236/psych.2017.810099

Received: June 12, 2017

Accepted: August 3, 2017

Published: August 7, 2017

Copyright $\odot 2017$ by author and Scientific Research Publishing Inc. This work is licensed under the Creative Commons Attribution International License (CC BY 4.0).

http://creativecommons.org/licenses/by/4.0/

\begin{abstract}
The article is based on an interview with Prof. Miguel Ángel Roca Perara, University of Havana about psychological intervention in Cuba. Trough out his professional career as a clinician and professor, he discusses the different psychological approaches as well as several types of psychotherapy in order to help improving the well-being of clients in Cuba, highlighting the major psychological problems in the country. Cognitive Behaviour Therapy and Rational Emotive Behavioural Therapy are specially recognized as the more useful to be used in psychological intervention.
\end{abstract}

\section{Keywords}

Causes of Stress in Cuba, Clinical Psychology, Health Psychology,

Psychotherapy in Cuba, Psychological Approaches, Rational Emotive

Behaviour Therapy

\section{Introduction}

Dr Miguel Ángel Roca Perara is Professor of Psychology at the University of Havana. As a prolific investigator and author, he has integrated into his academic work a unifying view that has enabled him to branch out into widely diverse theoretical frameworks, extracting from each the most effective resources for his professional activity. In this interview, he recounts his journey toward Cognitive Behaviour Therapy and explains the characteristics most relevant in psychological intervention in Cuba. Learning from several sources and investigating different psychological approaches, Dr. Miguel Ángel Roca Perara’s work 
is a significant contribution on understanding how human beings by thinking, feeling and acting in accurate ways can diminish their emotional disturbance even when everyday life is not easy.

\section{Havana, September 2016}

As the taxi made its way through the streets of Havana towards Dr Roca's residence, I recalled the words Ketty Castillo, author of the book "I'm off to Cuba" (Castillo, 2015) had lovingly dedicated to me in a copy a few days before my trip to the island, which included a phrase attributed to Columbus: "This is the most beautiful land that human eyes have ever lain upon" (Castillo, 2015). I got out of the taxi in front of a house surrounded by a leafy garden and on entering it a smiling woman came out to greet me. A fellow psychologist, she was the wife of Dr Roca and proceeded to describe each of the beautiful, sumptuous fruit trees. While we waited for her husband, she invited me up to the rooftop terrace where she pressed several pieces of fruit into my hands.

Up there above, wandering around on the roof of her house, I thought of how convenient it is to raise one's focus in order to gain a degree of perspective of oneself. This thought turned out to be a prelude to what Dr Roca would disclose a few minutes later: the stress caused by our corrosive everyday lives is lessened when contemplated with a degree of perspective. In the shade of the fruit trees and armed with several psychology books that he frequently put down on the table, Dr Roca related his professional career, characterised by the versatility of a man with the Renaissance curiosity of wanting to know everything, so enamoured he is of his work and of life.

M.R.: Professor, what can you tell me about psychology in Cuba?

M.A.R.: In my teaching activity, I teach Clinical Psychology, which is taught in the second year in the Faculty of Psychology. I've been teaching for 40 years. The College of Psychology at the University of Havana was founded in 1962 and was affiliated with the Faculty of Sciences until 1976 when it became a faculty in its own right. I graduated in 1977 and I've been there ever since, dedicating my entire life to the Faculty. In the world, many academics have no clinical experience, but here we have the advantage of having a clinic, the Centre for Guidance and Psychological Care (Centro de Orientación y Atención Psicológica), where we provide continuous psychological assistance, which enables a close relationship with the profession in addition to one's academic obligations. Cuba has an outstanding health system that is incredibly efficient despite the economics constraints. There's a big demand for clinical psychology and here in Cuba there's a culture that psychologists are not for the mad but professionals who help in a great deal of problematic issues.

M.R.: You say you are grateful to the profession for having enabled you to live many lives.

M.A.R.: I say this to my students because that's what I think. Each person who seeks out my services is, for me, a challenge, a new problem to collaborate with 
them for the sake of their well-being. Also, each one always teaches me something new, which allows me to grow not only professionally but also personally.

M.R.: Is this way of thinking related to the global view you have of the profession?

M.A.R.: Effectively, yes. Clinical Psychology has taught me that what's important in working with people is to adjust the procedures to the people instead of adjusting people to the procedures. This latter approach would be to ignore individuality and to subject them to a type of straightjacket tailored to the theoretical paradigms, as postulated by the so-called procrustean bed. I'm not against clinical specialization, but it seems absurd to cling to certain theoretical approaches while excluding all the others.

M.R.: Even though they may be antagonistic?

M.A.R.: Yes, I believe that in life it's not just a case of learning to live with differences but to grow to love oneself, even... or at least try to before being absolutely certain of such a radical antagonism, which does lead to exclusion. I think we need to value what the various approaches can provide because something useful can be learnt from all of them, especially for the client. We need to be open, not only in our professions but also in our lives. George Orwell in his book "1984" said "orthodoxy means not thinking" (Orwell, 1949). I fully subscribe to this opinion. He who only knows one thing doesn't even know that. I'm resolute in my way of seeing life and loyal to my convictions, but I've learnt well to distance myself from every dogma. I don't like adhering to just one model, I don't like saying that there's only one truth or that this is the best, I venerate the concept of alternative, I'm for respecting diversity in the sense of transcending the limits of training itself and professional obligations. My endeavour lies in nourishing an attitude of searching out everything that fosters the well-being of not only the client but also ourselves as people.

M.R.: An integrative world-view?

M.A.R.: Yes, but taking into account that integrating isn't the same as coming up with unjustified combinations or taking bits of techniques from different orientations or a slapdash eclecticism. Integrating means looking for common features while incorporating the contributions of each school whose efficacy has been demonstrated, being open to everything that can strengthen clinical efficacy independently of theoretical roots. From this core world vision, it's about making the most of the best and most valuable scientific output even though it may have been conceived from a different perspective of the world. Or, as Arnold Lazarus referred to when he talked of "the need to learn from the therapies that are in contact with clinical reality, independently of whether they belong to a specific orientation", that "it is empirical efficacy and not the therapeutic school that should determine the intervention procedures to be followed" (Lazarus, 1995).

M.R.: Eclecticism also has its detractors.

M.A.R.: Sure, because many people understand it as an amalgam of under- 
standings and a simple empirical sum of skills from the mere criterion of an apparent pragmatism. But this idea of eclecticism isn't serious or rigorous or scientific or even pragmatic. I believe in a dialectically, historically and culturally oriented epistemology focused on the individual. There is a theory here that says that life is a pyramid in which you are very good at two or three things, reasonably good at four or five and very bad at the rest. Integration, which is not the same as eclecticism should also avoid being triumphalist in the sense of proclaiming, my unifying perspective is the best! Because we'd be making the same mistake. It's better to talk of integration in psychotherapy, rather than psychotherapy of integration. Respecting diversity means accepting different perspectives, to rethink them, to extract from the general what you can specify with the client, who ultimately is the one who matters. Although it's evident you can't be good at everything and that you need to have one thing as your forte.

M.R.: How does this vision translate into your professional activity?

M.A.R. : It does it in a completely way. I've even been qualified on more than one occasion as extremely pragmatic, something which I like more than dislike, I have nothing whatsoever against any contribution by psychology or other sciences and branches of knowledge, and first I stop to see what benefit I can take from them before looking for their shortcomings. I agree with José Martí and think that the sun has many spots. The ungrateful focus on the spots the grateful focus on its light. And I tend to be like that in my personal life too. I'm committed to perfectibility and constant change and not to perfection and the static... although I have to recognise that I'm inflexible-implacable, maybe?towards human suffering and the extreme lack of ethics.

M.R.: Academic, publisher, clinician. Which activity do you feel most comfortable in?

M.A.R.: The three are part of the same thing. Writing is the putting into words the accumulated experience and research. As a clinician I work in the care centre associated with the Faculty. Teaching has been the fundamental meaning of my working life for its many rewards, but I don't think you can teach or write about psychology if you don't have clinical experience with people, and in this I've been very demanding of myself and have never stayed away from professional practice.

M.R.: And what is your strong point in these areas?

M.A.R.: Although I like to know a little of everything, I think you need to take sides because, as Dante Alighieri said in "The Divine Comedy": "the worst of the circles of Inferno is reserved for the neutral, those who don't take sides" (Alighieri, 1868), and my strong point is Cognitive Behavior Therapy (Beck, 2013). I like explaining to my students that I've had two great therapeutic girlfriends, Client-Centered Therapy (Rogers, 1962, 1965) and Cognitive Behavior Therapy (Beck, 2013). When I graduated and found myself for the first time in front of a client I felt so unsure, I thought: How on Earth can I help this person? I don't know anything about anything! In those days I still had the medical mentality of 
immediate prescription that I had to give the clients something quickly to alleviate their problems. My efforts lead me to Schultz's autogenic training for relaxation and I thought, this medicine is for everyone! And I prescribed it to every one of my clients. I could still give a formal class on autogenic training even now. I learnt it off by heart, I taught it to my clients in great detail but... I could never do it; I simply couldn't apply it to myself! And I then concluded: this is no good. I was 22.

M.R.: So what did you do?

M.A.R.: I then immersed myself in the work of Rogers. It was like my first love because it was a turning point for me professionally. Its philosophy of acceptance, understanding and genuineness and the basic conditions regarding the therapeutic process impressed me, since they broke with the models that considered humans as being governed from within by their impulses and externally by a hostile society.

M.R.: Dou you think that therapy is nothing more than a conversation carried out during the session?

M.A.R.: Indeed. Rogers said, "Psychotherapy is a relationship" (Freedman, Kaplan, \& Sadock, 1982). But I don't like waiting for things to happen. If I can do something I do it, in the sense of pushing the client towards a change for the good. I respect people's individuality highly, but only to a certain degree because if I can tell them how to live a little better I don't hesitate in intervening. I may be wrong but I don't keep it to myself. PCT currently enjoys a more active participation due to the influence of other models, but in those days it wasn't so, and I thought: This is no good either.

M.R.: And you changed direction.

M.A.R.: I flirted with behavior therapy but it didn't go much further. I genuinely believe it serves in certain cases and for certain things but it is very dehumanizing, something its own history has demonstrated. I then had other affairs, such as Transactional Analysis, Perls' Gestalt Therapy, Mahoney's Constructivism, and a number of others. And finally I came across the behavior cognitive therapies, in particular Ellis' Rational Emotive Behavior Therapy (REBT) and I realised that it was more like me, that it fitted in with my way of thinking and acting professionally. It involves direct actions, which are an important part of my world vision.

M.R.: Tell me what fascinated you about REBT.

M.A.R.: It's an integrated therapy: thought, emotion, behavior. It considers the human being in all its complexity. REBT is not a way of treating people to cure them but an eclectic existential philosophy, encouraging/persuasive, logical, active/directive, centred mainly on the here and now, which enables people to live more productively and with greater well-being. You studied in the Albert Ellis Institute and know perfectly that Ellis revolutionized much of psychotherapy, not only through his scientific contribution but also in his direct way of dealing with the client from an intelligent world vision or, as I sometimes like to say, 
from a de-imbecilizing philosophy.

M.R.: REBT empowers people by making them aware of their capacities and by teaching them to develop themselves.

M.A.R.: That's how I understand psychotherapy. When somebody goes to a psychologist, they don't go to see them to pass the time they go because they have a problem and hope to find a solution. Ellis taught us to show the client that the solutions lay in their hands, that if they change their way of thinking, they will change their emotions, their behavior, their life (Ellis, 2005). REBT does indeed empower people so long as they are willing to put themselves into it. Remember that nobody can do for somebody what that somebody cannot or does not want to do for themselves. It's the people themselves that hold the key that will open the door to a more mentally and emotionally healthy life, we only teach them how to do it.

M.R.: Ellis was a very particular person, and his way of interacting with clients could be disconcerting for them.

M.A.R.: Yes, even his physical appearance resembled not only his personal characteristics but also his way of conducting psychotherapy, which was alien to any conventionalism. I remember a lovely story of Ellis's in which he was with a client, who kept on verbally expressing everything she was thinking, going over the same issue again and again getting nowhere, when he snapped at her and said something like that: Madam, you and I are not here for romance, and until you come out of your mental garbage you won't do anything. When shall we start? With ideas like this REBT fascinated me, and I committed myself to it and in general to the wider spectrum of Cognitive Behavior Therapy.

M.R.: Do you think that the best therapy is that which works for a particular person?

M.A.R.: Gordon Paul said: "What kind of psychotherapy, administered by what sort of psychotherapist, for what kind of client, with what type of procedure and under what circumstances" (Paul, 1967). Problems we see in the clinic are practically universal, but each culture has its own specific peculiarities. What's more, individual singularity cannot be overlooked.

M.R.: What are the most common psychological problems in your country?

M.A.R.: It isn't really systematised. But I can tell you that in child psychology many children who receive treatment are the children of divorced parents and are generally neglected by one of them. In adults stress has a huge presence in Cuba at the moment.

M.R.: What are the distinctive features of stress in Cuba?

M.A.R.: I recently took part in a television programme on stress. I appear regularly in the media and on the radio I made about 400 editions of a programme called Talking Seriously. It was a friendly programme often live open and because it was not recorded, it allowed me to interact with people and I learnt a lot from this experience. I've also participated in television with programmes such as University for Everyone and Passage to the Unknown. In all cases in one way 
or another, the problem of stress has arisen. Only a few months ago we dedicated an entire programme to stress and they asked me if there was any stress in Cuba. My answer was yes there is, there's an enormous amount of economic stress. In the time you've been here you must have noticed it, you must have realised that the socio-economic situation is incredibly complicated.

M.R.: Which causes the many problems associated with that stress?

M.A.R.: Yes, that's right. Cubans are happy, optimistic people who love life but who are subject to high levels of stress every day. The activating events, as Ellis called them, are really strong here. We're talking about problems that go beyond the traditional clinic and have more to do with what a good colleague of mine calls corrosive everyday life, despite the fact that you see people joking, trying to enjoy themselves... but they carry an enormous amount of stress on their shoulders.

M.R.: How is stress from corrosive everyday life eased?

M.A.R.: In reality it's not at all easy, but it can at least be alleviated by contemplating it from a certain perspective. It's a stress that affects all of us. Let me tell you an anecdote: In the 1990s we went through what was known as the special period, which to me meant an especially bad period. One morning I was sitting at the bus stop waiting for a bus to the university deep in my own thoughts. Imagine my face when a while later a friend of mine arrived, looked at me sympathetically and said: Don't get depressed because it's massive. This is the real situation, looking for different perspectives that don't involve the resignation or conformity that despair implies. Thank goodness Cubans are so resilient and have a great capacity to adapt, are strong in terms of putting up with difficulties, because socially these conditions are not easy to bear. I don't think there's a generalised explosion, but uncertainty, yes.

M.R.: Are you referring to the anxiety associated with uncertainty?

M.A.R.: Exactly. This was the other subject addressed in that programme, the first was economic stress and the other was uncertainty. In our socio-economic model Cubans have spent years living from day to day and solving the problem using strategies employed by Alcoholics Anonymous. The anonymous alcoholic has a really interesting and intelligent procedure. The anonymous alcoholic doesn't say they are never going to drink again, what they say is: I'm not going to drink in the next 24 hours, and this causes less anxiety because they believe that if they can tolerate being sober for 24 hours, then they'll see... Cubans have spent years living like that, trying to deal with everyday life efficiently, and to be fair, our idiosyncrasy contributes to this... in spite of everything.

M.R.: What are the secondary emotions associated with stress and uncertainty?

M.A.R.: Lazarus has a very interesting theory about stress that, from a cognitive point of view, is one of the ones I most like. He says that stress is a macroconcept he calls it a subsystem of emotions. In other words, it doesn't present itself as one big emotion but as three basic clinical emotions: anxiety, depression 
and anger, to which can be added the four most important unhealthy negative emotions associated with social life: shame, jealousy, blame and the most corrosive of all, envy. What we see here in the clinic associated with stress is exactly this salad of emotions: anxiety, depression and anger, although I don't think these are unique to the Cubans, they're universal, especially in western society. I imagine that these same emotions must be seen in clinics in your country. It's the same here, only the external events that trigger stress are different. Fortunately in Cuba our graduates have been working for years in health psychology and have been able to carry out great work in this area contributing favourably to what they call mental health in the population.

M.R.: Tell me how they did this.

M.A.R.: At the end of the 1960s there was a group of in my opinion brilliant psychologists, very progressive people with a very open mentality for that era, who started a process of breaking away from traditional clinical psychology and opted for a model of health psychology. It's an effective and efficient model in which the role of the psychologist doesn't stop at the traditional clinic door but is present in practically all health institutes in the country. Within this model we had psychologists in all levels of health-clinics, hospitals, research centres, etc., throughout the entire health spectrum imaginable a psychologist was present at that time. In addition to this, psychology didn't stop at trauma or conflict but included many other areas related to health: mourning preparations, care of transplant clients, terminal stages of various illnesses, consequences and limitations due to accidents or diseases. If you go through all the research you'll see that we've worked with diabetics, clients with high blood pressure, invalids. I myself did my PhD thesis on Psychology and Cancer. It's a very wide intervention spectrum that's related to the salutogenic model. It became a solid model that's now sadly in crisis because a not insignificant number of competent psychologists have emigrated to other countries in search of better living conditions, while others have "emigrated" within Cuba to jobs that are better paid but that are outside of the clinic.

M.R.: Is this model based on a bio psychosocial perspective?

M.A.R.: Of course. From this perspective health becomes something you gain by paying attention to biological, psychological and social needs. The mind and the body cannot be distinguished in issues of health and illness because both evidently influence a person's state of health. Life is systemic, everything is connected and an imbalance in any one of these planes can manifest itself in another. None of them should be neglected.

M.R.: Give me an example.

M.A.R.: I can give you several. High blood pressure is common in this country. Diabetes is also a big cause for concern. Both are closely linked with psychologi$\mathrm{cal}$ and social factors. Another recent issue very serious and common throughout this country, is that of carers, people who have to look after dependent relatives who are severely invalided. Whether it's a father who's blind or who's got 
Alzheimer's, or a child suffering infantile paralysis, being a carer means you have no choice but to give up a good part of your daily life. The economic situation has an impact on the country's demographics, the number of elderly people is increasing and we are a country with a long life expectancy approaching 80 years. Before, the young used to say they would have a baby when the conditions were right, but these days these conditions barely exist. Young people are emigrating and if they don't emigrate and decide to stay here many decide not to have children or limit themselves to just one. Meanwhile the population is ageing. Looking at the issue transparently, with no political bias, we see that many of us who are between 45 and 65 years old have children who live overseas. Right now I have to look after my elders, but I'm nearly elderly myself although I try to hide it. I'm 61 but I feel more like 20. But what will happen the day I no longer feel like a 20 year old and I look over my shoulder and ask myself: Who is going to look after me? It's possible that there won't be anybody. This is the problem that public health is already forecasting: the carer, although a carer, has nobody to care for them. In a few years' time we're going to be overrun by old people in this country and these social conditions cause stress. As you can see, stress is everywhere you look.

M.R.: And when you're stressed, irrational thought multiplies.

M.A.R.: Indeed. In recent years, Ellis stressed a controversial issue which is that human beings come into this world predisposed to irrational thoughts. I personally think that it's their culture that teaches them to think irrationally. Humans contort themselves to an incredible degree just to be accepted. Remember the Rogerian concept which is also found in Ellis' model, about the need for unconditional acceptance. People start to think irrationally in order to please other people's expectations and to be positively accepted by them. I also think as Ellis did that in our culture a child learns to be a correct thinker before learning to think. That's why I like Ellis' cognitive-behavior outlook as much as Beck's, which puts the "I ought to" before the most varied of human dilemmas. And this is cultural. We aren't born programmed to think irrationally. The culture, the context, the everyday situations we have to deal with are a big source of irrational ideas.

M.R.: Having an opened mind-as we said at the beginning-helps to avoid limiting ourselves.

M.A.R.: You need to question everything. Values that are assumed to be good but that are rarely questioned make their way into our heads from infancy and by repeating them, they become true. I sometimes like to think like a statistician: not accepting the true hypothesis but rejecting the null hypothesis, which means you always leave the door open to nonsense and the absurd, because you can think that this nonsense, this irrational idea, shouldn't exist but there it is and the fallacy of rationality falls apart. We human beings love to think that life has to be logical and fair, but life's neither fair nor logical, life is how it is whether we're aware of it or not. 
M.R.: What about Jung's concept stating that everything that is not made conscious ends up manifesting as destiny?

M.A.R.: A few years ago, the academic orthodoxy stated explicitly that the subconscious doesn't exist, that the higher level of behavior regulation or human conduct is the conscious.

M.R.: And what do you think?

M.A.R.: I think an important subconscious dynamic does exist, but I resist making it absolute. Someone said that when you're not sure about something, doubt, but when you are sure, doubt even more. Some of the contributions of Psychoanalysis, one of the models in which the subconscious has a greater presence, are in my opinion undeniable, but become negative when taken to extreme fatalistic positions: the role of the subconscious in determining someone's behavior and subjectivity is indisputable, but it is highly debatable whether man is a blind slave to the designs of subconscious structures and is unable to consciously direct his activity in terms of consciously established goals. They are not the disguised expression of subconscious motives!

M.R.: There are still many concepts that we cannot explain through science.

M.A.R.: Certainly. I think it was Einstein who stated that man would understand space first then the insides of the Earth and himself last, although we need to start to try now. As scientists we need to be cautious and accept that there remains much to learn. For example, a highly controversial concept in psychotherapy and in life is whether intuition exists or not. Methodologically it's not a concept that can be captured, and has even been called into question for this very reason, but we know it exists. I can't demonstrate it to you scientifically but there is that sense that tells you something is happening here. When you feel that something strange is going on, listen to what your body is telling you, the Rogerian idea when talking about the organismic evaluation is that the mind is very limited but the body is extremely wise. I've only just met you but straightaway I feel comfortable talking to you and I don't know why, it's not a rational process, it's intuitive.

M.R.: Some scientists are beginning to postulate that the mind doesn't just reside in the brain, that it affects every cell in the body.

M.A.R.: I wouldn't dare say it, although cloning can be carried out from any cell in the body. And human beings are very complex. Although I'm deviating slightly from your question, I'm not of any religion but I like knowing and I know in depth books such as the Bible where at the beginning it says that God made man in the image of himself, that is, not equal to him but only his image. And as Silvio's song goes: It's the same, but it's not equal. But if God does exist, he is made of divine material, while we humans are made of a very complicated substance. All the same, there we are, trying to be optimistic and looking for happiness... without being certain of what cell it lies in, if in any.

M.R.: Are you optimistic when you look at people?

M.A.R.: José Martí who is the figure I most respect in the history of this coun- 
try had faith in human improvement, It isn't an act of knowledge it's an act of faith. One likes to believe that human beings have good parts that in some moment will impose themselves. But good intentions pave the way to Hell because one thing is good intention and the other is reality. Reality is sometimes very complicated. I believe every one of us has at least one tiny piece of something good although it's not always easy or desirable to show it. Remember that people don't like to be free because being free makes you responsible, as Fromm suggested. When you are free you say to yourself well: My life is my business, and it's not always so simple. A good colleague of mine used to say that from a certain age every one of us is responsible for our own lives and even our own faces, which is why people age according to the way they live.

M.R.: Do you mean that is the face the mirror of the soul?

M.A.R.: I would say so, yes. In the style of the classic literary work "A Picture of Dorian Gray" the face isn't so far from the way we behave in our lives and in it are pictured both the good and the bad. But I repeat: I have never liked accepting that there is only one truth.

M.R.: This emphasis of yours on change, diversity and alternatives, does this have anything to do with your professional training?

M.A.R.: Yes, I think so. I'm usually quite anti-establishment, but I'm all in favour of thinking in dialectic terms. I don't think it's desirable to renounce dialectics because what it teaches you for your profession and your life is impressive. Talking in Ellis' terms I'm not telling you that dialectics "should" be studied but... let's just say it's highly desirable. Dialectics is quite hard going, but once you overcome this you realise that its basic laws-the transformation of quantitative change into qualitative, the unity of opposites and the denial of denial-are universal in nature, society and people. Nearly everything in life is explained by these laws. And the dialectic pairs are formidable, quantitative-qualitative, ethics-aesthetics, cause-effect, essence-phenomenon... despite their apparent contradiction.

M.R.: Do you think that contradictions are the engine that makes things work?

M.A.R.: Yes, I would say so. Each pair seems to contradict the other but none could exist on its own. They need each other. Life and especially development cannot be thought of without contradiction, life becomes paralysed if there isn't a counterpart that defies the established and that calls for growth. Darkness can't be understood without knowing light. We value well-being more after a period of adversity. But for most people a philosophy in which nothing is static, that obliges you to be responsible for your life and to put your things in order, is difficult. It's easier to say: "I'm stressed and I control my anxiety through medication" than to say: "It's me who has to face up to this and put my things in order". I think that philosophy, especially dialectics with its emphasis on opposites, is of great importance in learning to think, feel and live effectively and efficiently. A few years ago I read a popular book whose title says it all: "Plato, Not Prozac!" 
(Marinoff, 1999), Ellis knew this well.

M.R.: And he insisted that we shouldn't take ourselves or life so seriously.

M.A.R.: He would certainly have agreed with this joke we psychologists use: Stress only has two rules in order to deal with it: First, only get stressed for important things; Second, nothing is important. To avoid being conventional, let's say "almost nothing", because a life without projects in which to immerse ourselves-although even these involve a certain degree of good stress, a life without optimism, without a sense of humour, without laughter, would surely be incredibly boring.

\section{Conclusion}

Everywhere on Earth, every human being tends to think that there is a perfect correspondence between what we see and what actually exists. However, our perception of the world is not a photographic representation but our personal view of it. What we call reality is only our own perspective of the facts, dressed with cultural and also personal cognitive habits that configure a system of cognitive beliefs. Cognitive Psychology emphasises that we must acknowledge our beliefs in order to realise how they distort reality. Investigating, discovering, questioning our beliefs, opening ourselves to the possibility of incorporating a new way of thinking is one of the keys to achieve psychological well-being. We cannot always change our circumstances, but we can decide how to respond to them.

\section{References}

Alighieri, D. (1868). La Divina Comedia. Barcelona: Centro de Reparticiones la Ilustración.

Beck, J. S. (2013). Cognitive Behavior Therapy: Basics and beyond (2nd ed.). New York: The Guilford Press.

Castillo, K. (2015). Me voy pa Cuba. El Puerto de Santa María: Ediciones El Boletín.

Ellis, A. (2005). The Myth of Self-Esteem: How Rational Emotive Behavior Therapy Can Change Your Life Forever. New York: Prometheus Books.

Freedman, A., Kaplan, H., \& Sadock, B. (1982). Tratado de Psiquiatría (3rd ed.). La Habana: Edición Revolucionaria.

Lazarus, A. A. (1995). Integration and Clinical Verisimilitude. Clinical Psychology: Science and Practice, 2, 399-402. https://doi.org/10.1111/j.1468-2850.1995.tb00051.x

Marinoff, L. (1999). Plato Not Prozac! New York: HarperCollins.

Orwell, G. (1949). 1984. Washington DC: The Dramatic Publishing Company.

Paul, G. L. (1967). Strategy of Outcome Research in Psychotherapy. Journal of Consulting Psychology, 31, 109-118. https://doi.org/10.1037/h0024436

Rogers, C. (1962). On Becoming a Person: A Therapist View of Psychotherapy. Boston, MA: Houghton Mifflin Company.

Rogers, C. (1965). Client-Centered Therapy. Boston, MA: Houghton Mifflin Company. 
Submit or recommend next manuscript to SCIRP and we will provide best service for you:

Accepting pre-submission inquiries through Email, Facebook, LinkedIn, Twitter, etc. A wide selection of journals (inclusive of 9 subjects, more than 200 journals)

Providing 24-hour high-quality service

User-friendly online submission system

Fair and swift peer-review system

Efficient typesetting and proofreading procedure

Display of the result of downloads and visits, as well as the number of cited articles Maximum dissemination of your research work

Submit your manuscript at: http://papersubmission.scirp.org/

Or contact psych@scirp.org 